\title{
CONGENITAL DISLOCATION OF THE HIP
}

\author{
Lieutenant-Colonel J. T. COULL, M.B., Ch.B., F.R.C.S., R.A.M.C.
}

British Military Hospital, Rinteln

SUMMARY: The problems of diagnosis and management of congenital dislocation of the hip are discussed.

The importance of the care and supervision of splintage is stressed as is the need for adequate clinical and radiological follow-up of all suspect hips.

Arthrography is essential in all late cases.

A scheme of treatment is suggested.

\section{Introduction}

The establishment of an Orthopaedic unit for British Army of the Rhine (B.A.O.R.) in 1971 has enabled a study to be made of this condition in a military society. The diverse origins of such a society nullify any possible regional variations in incidence as suggested by James (1972). The population movement is far greater than in a comparable community in Britain, an average of one third changing each year making continuity of treatment and follow up more difficult. Almost all births in Germany are in military maternity units, the few born in German hospitals for logistic reasons being transferred within a week to a military unit and thus all neonates are available for examination of the hips. A further effect of population movement is that a large proportion of infants in Germany will have been born in Health Service hospitals in the United Kingdom or in other military hospitals.

\section{The neonatal problem}

Adequate treatment for congenital dislocation of the hip recognised at birth should give excellent results.

The maternity unit of the British Military Hospital at Rinteln has an average of 1,500 births annually. All infants are examined by the obsterical registrar on the third day using the Barlow modification of the Ortolani test. All suspect hips are re-examined by the orthopaedic surgeon on the following day and a plain radiograph of the pelvis with the legs adducted and in neutral rotation is taken.

During the period January 1972 to December 1973 seventy-three infants were referred from a total of 2,984 births. Those in whom a clunk was confirmed were classified as unstable. The remainder were classified as stable. this group containing those regarded as normal and a small group in whom a clunk could not be elicited, abduction was unrestricted but mild capsular laxity could be detected.

The unstable hips have been splinted in flexion and abduction for three months in a Stracathro type splint (MacKenzie 1972) made by the physiotherapy department in three sizes from Plastazote (Registered trade mark 'Bekelite Xylonite Ltd.') (Fig. 1). This splint has been entirely satisfactory. Double napkins have no place in the management of this condition. The stable group received no treatment. 


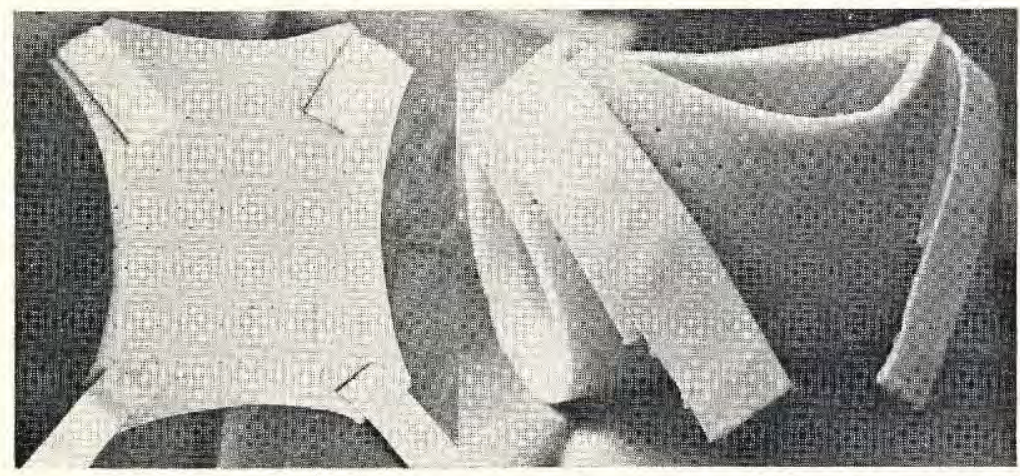

Fig. 1. The splint.

All children are followed up for at least one year with radiographs at six weeks, three months, six months and one year. The six week film for the unstable group is taken in the splint. Infants are discharged only when there is radiological evidence of concentric reduction of a normal capital epiphysis within a socket offering good roof coverage, a normal neck shaft angle and no excessive anteversion of the femoral neck.

The value of a plain radiograph has been confirmed (Figs 2, 3 and 6). Special views have not been taken.

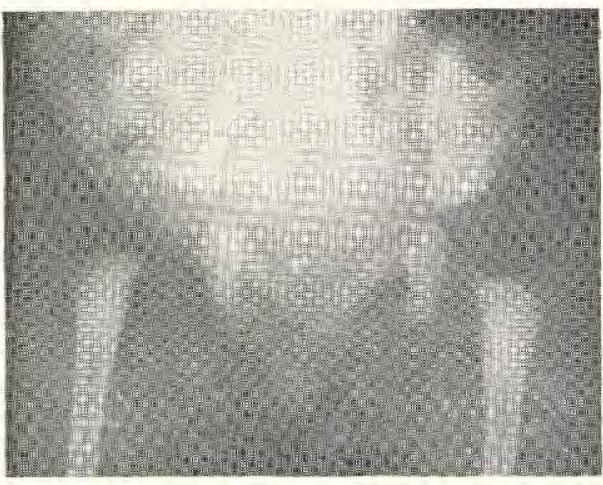

Fig. 2. Neonatal radiograph showing standing out on the right.

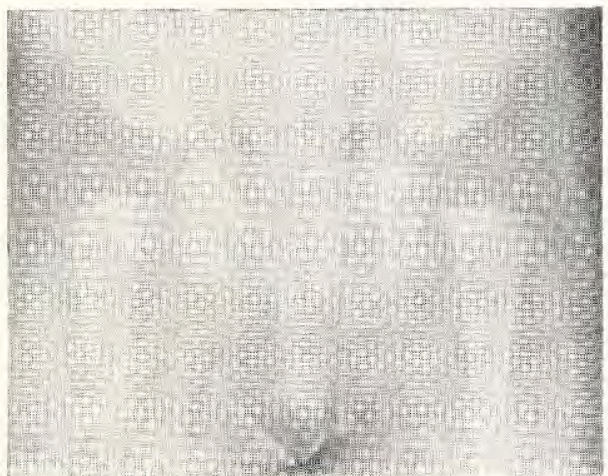

Fig. 3. The same child after splintage.

Two cases were clinically stable but the radiograph suggested slight standing out of the hips with anteversion and were splinted.

Two further cases were classified as stable but one showed standing out of the suspect hip at six weeks while the other developed subluxation without anteversion at six months. Both have been treated in casts in a modified Lorenz position. These were incorrectly classified and should have been splinted at birth. Another child was missed in the maternity unit but was fortunately recognised at two weeks when she attended the orthopaedic out patient department for a different reason.

All hips in the unstable group are satisfactory. No complications of treatment have been encountered. The significance of clicks in stable hips is not understood but 
they do not justify splintage. It is of interest to note, however, that there has been a slight but significant delay in the appearance of the capital epiphysis in 20 per cent of such hips although final development has been normal. It is acknowledged that a number of neonates have been splinted unnecessarily as the hips would have stabilised spontaneously. This must be accepted and there is no evidence that damage is incurred by splintage in the absence of acetabular obstruction.

The incidence of instability has been 5.3 per thousand births and of laxity 1.0 per thousand.

\section{Presentation in the first year}

In this group appear those cases where treatment from birth has failed, where some limitation of movement of one hip or shortening of a limb has been observed by the parents or as an incidental radiographic diagnosis.

In these late cases it is essential to recognise the existence of an inverted limbus, the development of which is shown (Fig. 4), as damage and deformity of the femoral

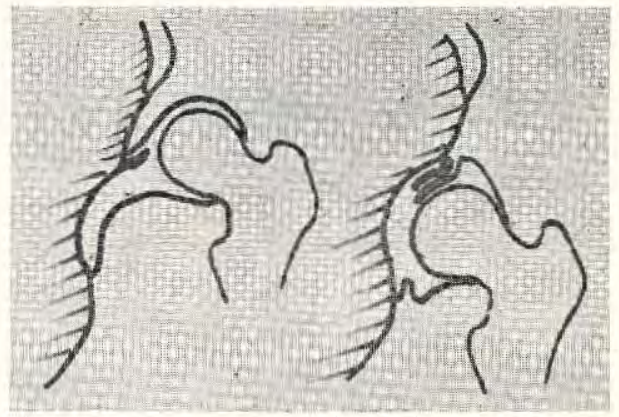

Fig. 4. Development of a limbus. The pressure of the displaced head on the stretched capsule and cartilaginous margin produces infolding into the empty socket.

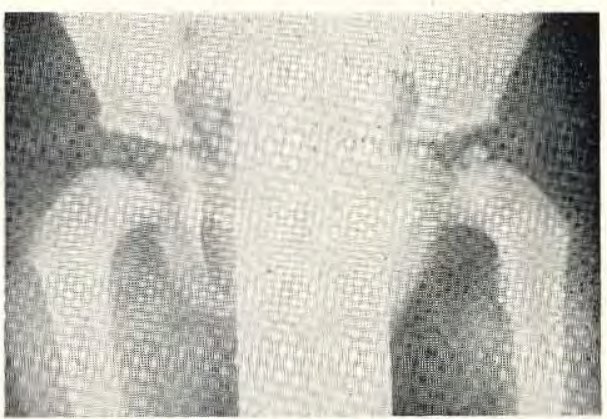

Fig. 5. Bilateral epiphyseal damage.

epiphysis and metaphysis may result from forced reduction in the presence of such an acetabular obstruction (Somerville 1957). The growing femoral head in infants of this age appears to be particularly vulnerable to pressure (Mitchell 1970). Arthrography is required to confirm the presence of a limbus and to outline its size. An example of an arthogram is seen (Fig. 12) and specimens of excised limbal obstruction are shown (Figs 11 and 14). A review by Gage (1972) confirmed that avascular necrosis as a complication increases with the age of the child and with the degree of abduction in splintage. This, however, is a rare occurrence in a hip where the limbus has first been removed. The late results of capital damage are seen (Fig. 5) in a boy of four years who had been treated conservatively from the age of ten months in casts in the full Lorenz position.

Seven children have presented at this unit in this age group with established dislocation or marked subluxation. Four had been recognized at birth. One had bilateral dislocations (Fig. 6) and had been treated in a von Rosen splint but only for one month. When referred to this centre at four months the right had stabilised but the left remained dislocated (Fig. 7). The hip was reduced on a double abduction frame. Arthrography 
revealed no significant limbus and plaster immobilisation followed by a derotation osteotomy has produced a satisfactory result (Fig. 8). Another failed because the aluminium cruciform splint was inadequate for the strength of the infant's legs and reduction had not been maintained. Two had been advised double napkins as the fitting of splints had proved unsatisfactory. The radiograph of one of these at ten months shows bilateral subluxation (Fig. 9). One child was brought to the clinic at five months by her mother who had read an article on the subject in a popular magazine and could demonstrate unilateral limitation of abduction. Another was undergoing treatment by the author for a tibial fracture. A radiograph taken on a rather large film included the hip and revealed subluxation.

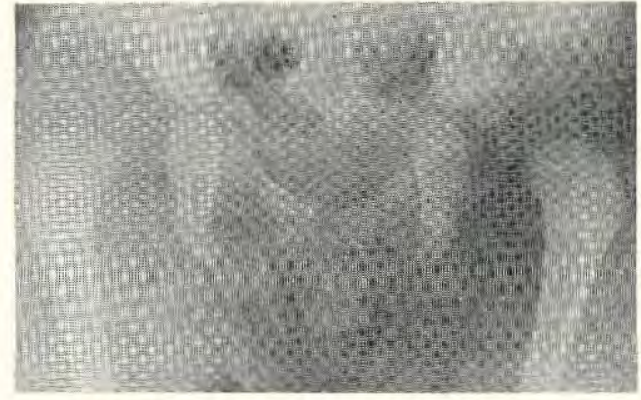

Fig. 6. Neonatal radiograph showing bilateral dislocation.

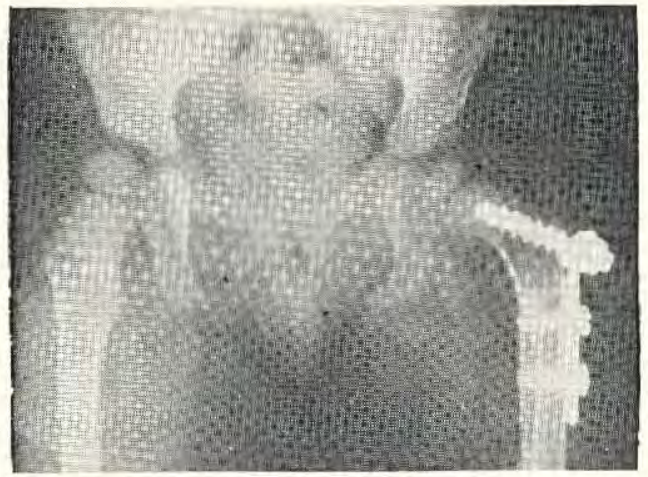

Fig. 8. The same case following frame reduction and femoral derotation osteotomy.

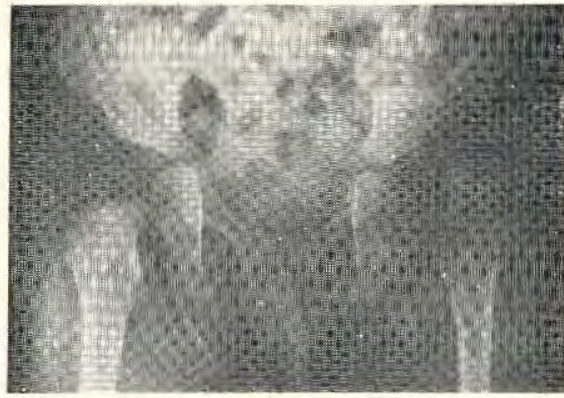

Fig. 7. The same case at four months-failed splintage.

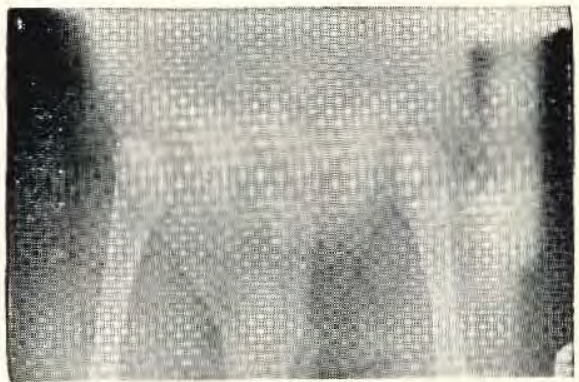

Fig. 9. Bilateral subluxation in a boy of ten months.

Treatment at this age involves, therefore, gentle reduction by traction, the removal of any significant acetabular obstruction, an adequate period of immobilisation in plaster and, in the older infant, the correction of persistent anteversion by femoral derotation osteotomy.

\section{Established dislocations presenting at walking age}

Twelve children have been seen in this category. Most of them had been taken to their practitioner at an earlier age on account of gait abnormalities but had been 
reassured without any X-ray examination. The bilateral dislocation is the more difficult to detect.

A gentle examination under anaesthesia is carried out at the start of treatment to assess soft tissue tightness but manipulative reduction is not advised. Almost all will have a large inverted limbus and many will have poor sockets in which normal development cannot be expected after reduction. Acctabular re-orientation may be required using the technique of innominate osteotomy described by Salter (1961), the details of which are shown (Fig. 10). The displacement of the lower fragment, which provides

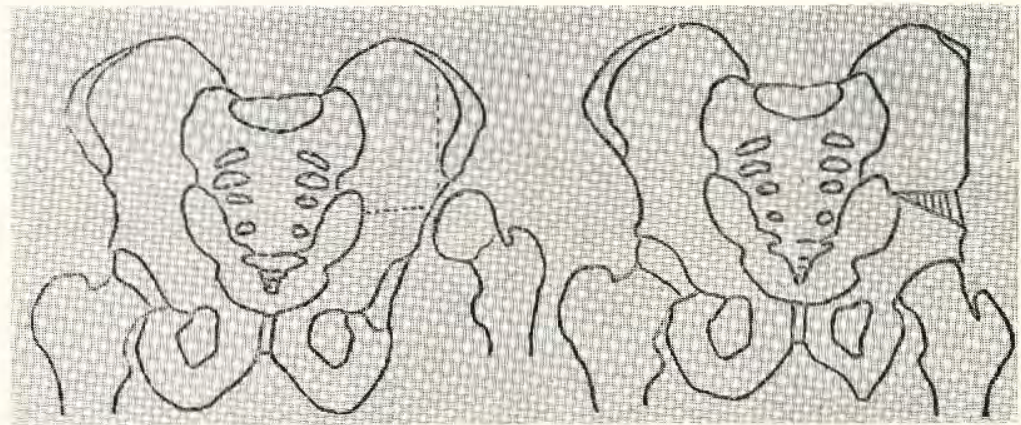

Fig. 10. The technique of Salter innominate oesteotomy.

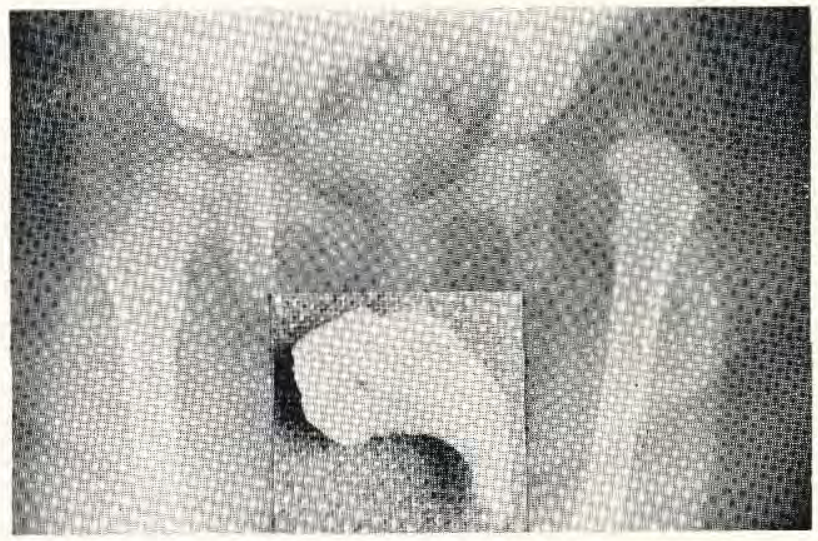

Fig. 11. A girl of sixtecn months with a left dislocation. Inset at life size shows the excised limbus.

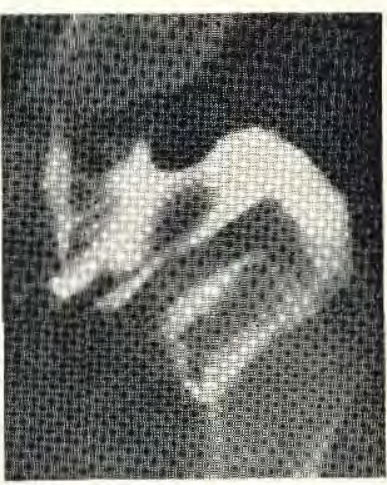

Fig. 12. The same case, the arthrogram showing the filling defect.

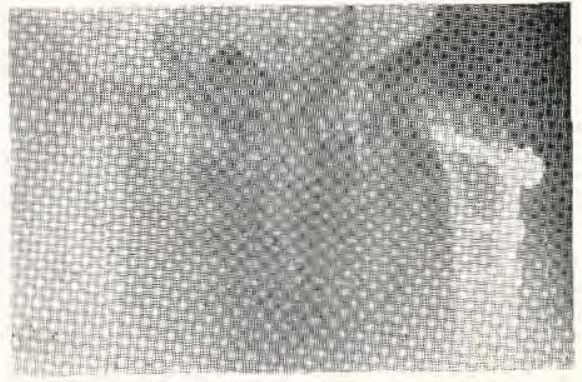

Fig. 13. The result in the same child following open reduction, excision of limbus and femoral derotation. 


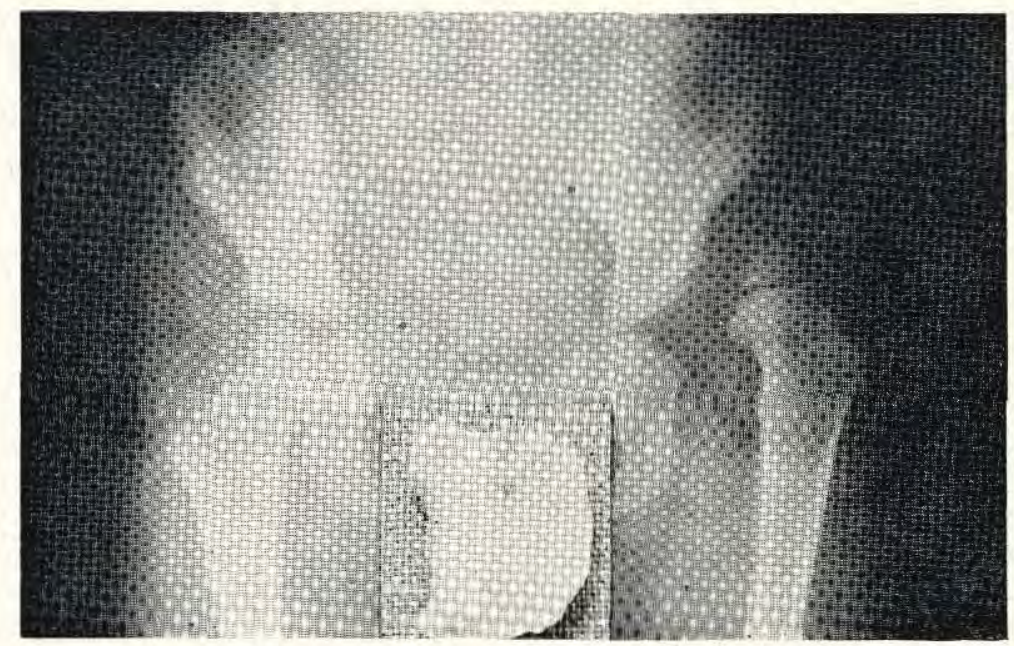

Fig. 14. A girl of $2 \frac{1}{2}$ years with a left dislocation, the inset at life size showing the excised limbus.

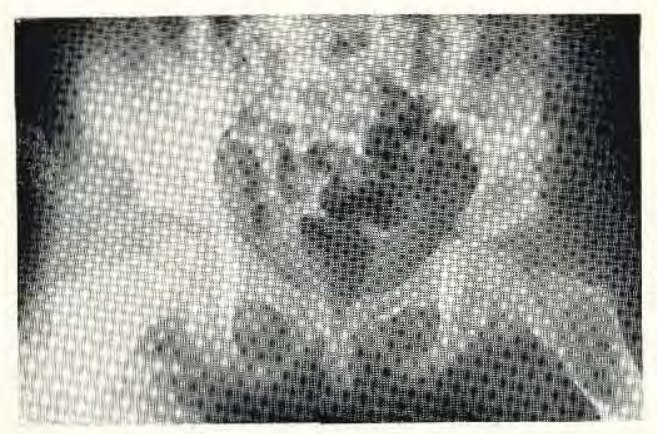

Fig. 15. The same child after open reduction, limbal excision and innominate osteotomy prior to femoral derotation.

improved roof cover and stability, is maintained by a large wedge graft cut from the anterior iliac blade.

Four have undergone innominate osteotomy and ten have required femoral derotation. All had significant limbal obstructions, the operative removal being combined with an anterior capsuloplasty. Redundant capsule is excised and the remainder is tightly closed over the reduced head. Only one hip reduced with sufficient ease to avoid the abduction frame. All have stabilised satisfactorily and no problems of avascular necrosis have occurred. The results of two of the children are shown (Figs. 11 to 15).

A summary of the scheme of management in this age group is given (Fig. 16).

The nineteen $(7+12)$ late presentations in this series have a sex ratio of seventeen female to two male. Five had bilateral dislocations and of the remainder, ten were left and four right. Only one had been a breech delivery but two had versions carried out. Nine were born in Health Service hospitals.

These late cases represent an incidence of established dislocations of just over 2 per 1000 births accepting an estimate of the population at risk in view of movement. This figure is disturbingly high and emphasises the need for diligent neonatal examination. 


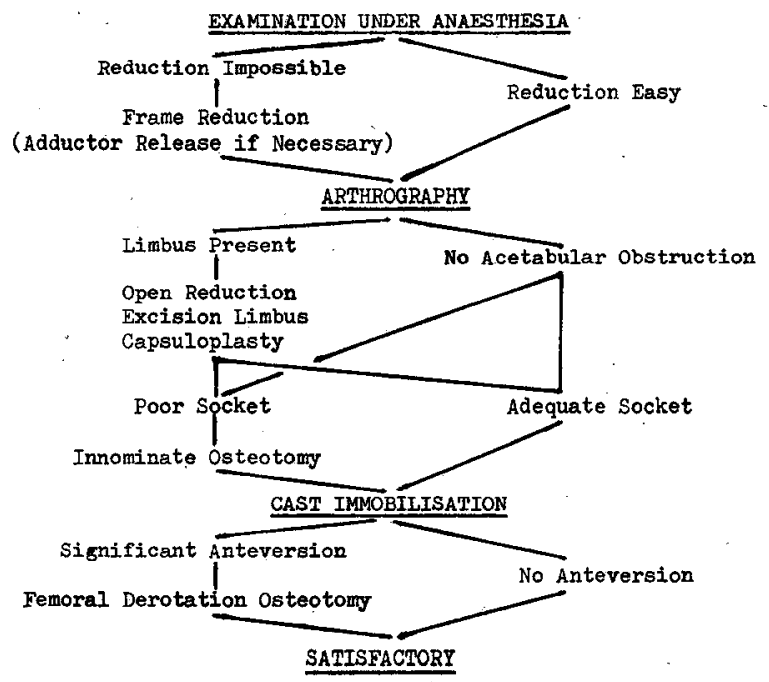

Fig. 16. Scheme of management.

The average referral age for toddlers was twenty months. Three children had affected siblings.

\section{Acknowledgements}

I gratefully acknowledge the help and enthusiasm of my surgical and obstetrical colleagues in this work and for the opportunity to treat their cases.

\section{REFERENCES}

Barlow, T. G. (1962). Early diagnosis and treatment of congenital dislocation of the hip. J. Bone $J t$ Surg. 44-B, 292.

GAGE, J. R. and WINTER, R. B. (1972). Avascular necrosis of the capital femoral epiphysis as a complication of closed reduction of congenital dislocation of the hip. J. Bone Jt Surg. 54-A, 373.

JAMES, J. I. P. (1972). Editorial. Congenital dislocation of the hip. J. Bone Jt Surg. 54-B, 1.

MacKenZIE, I. G. (1972). Congenital dislocation of the hip. J. Bone Jt Surg. 54-B, 18.

Mrtchell, G. P. (1970). Congenital dislocation of the hip. Scot. med. J. 15, 468.

Ortolani, M. (1937). Un segno poco noto e sua importanza per la diagnosi precoce di prelussazione congenita dell'anca. La Pediatria 45, 129.

SALTER, R. B. (1961). Innominate osteotomy in the treatment of congenital dislocation and subluxation of the hip. J. Bone Jt Surg. 43-B, 518.

Somerville, E. W. and ScotT, J. C. (1957). The direct approach to congenital dislocation of the hip. J. Bone Jt Surg. 39-B, 623.

\section{Royal College of Midwives}

Colonel B. A. Gavourin, F.R.C.S., F.R.C.O.G., was elected to the Examining Board of the Royal College of Midwives. 